\title{
Coinfection Of HIV With HBV And HVC In A Low Resources Setting M Hojman* ${ }^{* \ddagger}$ C Perez and ML Ordoñez
}

Address: Servicio de Infectología, Municipalidad de Malvinas Argentinas, Pcia. de Buenos Aires, ARGENTINA

* Corresponding author $¥$ Presenting author

from 2005 International Meeting of The Institute of Human Virology

Baltimore, USA, 29 August - 2 September 2005

Published: 8 December 2005

Retrovirology 2005, 2(Supp| I):S9I doi:I0.1/86/1742-4690-2-SI-S9I

\section{Background}

Co-infection of HIV with HVB and C is well described in medical literature from all over the world. The coexistence of these infections can worsen the evolution of anyone of them, therefore a fast diagnosis and treatment can help to achieve a better prognosis. Malvinas Argentinas County is a low resources seting located in NW of Buenos Aires Province. Objective: Determining the existence of coinfection with HIV and HVB and/or HVC in patients (p) included in the Municipal Program Against HIV and establishing the characteristics of the infected population.

\section{Methods}

Prospective study of HIV + p regarding the presence of positive serology for HVC (ELISA), HVB (determination of HBsAg) or both.

\section{Data obtained}

Sex and risk factor for HIV infection (heterosexual, homo/ bisexual, intravenous drug use (IDU).

\section{Results}

Of 162 p, 15 were HVC+ (9.3\%), 13 HbsAg+ (8\%) y 2 HVC/HbsAg+ (1,2\%). 13 HVC+ were male $(87 \%)(p=$ 0.007 ), and among them, risk factor for HIV acquisition was IDU in 9 cases $(60 \%)$ and heterosexual risk behaviour in 6 (RR 12 -IC: 4,83<RR<29,79; p0,0005). $11 \mathrm{HbsAg+}$ were male $(84.5 \%)(\mathrm{p}=0.005)$ and among them risk factors for HIV acquisition were heterosexual risk behaviour in 5 cases, homosexual risk behaviour in 6 cases and IDU in 2 cases, none of this were significant as relative risks.

\section{Conclusion}

Male sex was a significant relative for coinfection on HIV with HBV and HVC, maybe related to IDU in this population. IBU as a risk factor for acquisition of HIV was signi- cant for coinfection with HCV. Warning about HCV coinfection should be adopted in this improve the prognosis of both infections. 